\title{
Heterophils to Leukocytes Ratio Measurement
}

National Cancer Institute

\section{Source}

National Cancer Institute. Heterophils to Leukocytes Ratio Measurement. NCI

Thesaurus. Code C116187.

The determination of the ratio of heterophils compared to leukocytes present in a sample. The measurement may be expressed as a ratio or percentage. 